\title{
Comparative Pharmacokinetics of three major bioactive components in rats after oral administration of Typhae Pollen- Trogopterus Feces drug pair before and after compatibility
}

Huiting Zeng ${ }^{1,2,3}$, Ping Xue ${ }^{1,2,3}$, Shulan $\mathrm{Su}^{1,2,3,4^{*}}$, Xiaochen Huang ${ }^{1,2,3}$, Erxin Shang ${ }^{1,2,3}$, Jianming Guo $0^{1,2,3}$, Dawei Qian ${ }^{1,2,3}$, Yuping Tang ${ }^{1,2,3}$ and Jin-ao Duan ${ }^{1,2,3,4^{*}}$

\begin{abstract}
Background: Typhae Pollen (TP) and Trogopterus Feces (TF) are well-known traditional medicine in china which widely used for thousands of years as drug pair called Shixiao San for treatment of blood stasis syndrome, specially shown great efficacy in gynecological disease. Typhaneoside, vanillic acid and p-coumaric acid are the main bioactive components of Typhae Pollen. This study was carried out for comparing the pharmacokinetic profile of these three major bioactive components in rats after oral administration of Typhae Pollen-Trogopterus Feces (TP-TF) drug pair before and after compatibility.

Methods: A sensitive and rapid UPLC-TQ/MS method has been developed for simultaneous quantification of the three main bioactive compounds in blood at different time points after oral administration of Typhae Pollen (TP) and the combination with Trogopterus Feces (TF).

Results: There were significant differences of $C_{\max }, T_{\max }, T_{1 / 2}$ and $A \cup C_{0 \sim t}$ for three bioactive compounds among the groups, for typhaneoside with the most highest plasma concentration of $370.86 \pm 315.71 \mathrm{ng} / \mathrm{mL}$ and more longer $T_{\max }$ in TP-TF co-decoction group $\left(\mathrm{C}_{\mathrm{M}}\right)$; for vanillic acid, TP-TF co-decoction group $\left(\mathrm{C}_{\mathrm{M}}\right)$ had a good absorption with $C_{\max }(3870.99 \pm 2527.99 \mathrm{ng} / \mathrm{mL})$ and $T_{\max }(1.47 \pm 3.20 \mathrm{~h})$; for $p$-coumaric acid, it had similar pharmacokinetic characteristics with vanillic acid.
\end{abstract}

Conclusions: The three bioactive components in Typhae Pollen (TP) were simultaneously determined by UPLC-TQ/ MS and had a good absorption in rat plasma after the combination with Trogopterus Feces (TF).

Keywords: Typhae Pollen-Trogopterus Feces drug pair, Typhaneoside, Vanillic acid, p-coumaric acid, Pharmacokinetic, UPLC-TQ/MS

\footnotetext{
*Correspondence: sushulan1974@163.com; duanja@163.com

${ }^{1}$ Jiangsu Key Laboratory for High Technology Research of TCM Formulae,

Nanjing University of Chinese Medicine, Nanjing 210023, China

Full list of author information is available at the end of the article
} 


\section{Background}

Blood stasis (BS) is considered as a familiar type of clinical symptoms and signs in Traditional Chinese Medicine (TCM) for thousands of years, which is the underlying pathology of many disease processes according to TCM theory. Generally speaking, Blood stasis (BS) refers to retarded blood flow and it is often associated with disruption of heart Qi (vital energy), thus giving rise to a series of hematological disorders such as congestion, hemorrhage, thrombosis, local ischemia (microclots) and even tissue changes [1, 2]. It mainly manifested as pain, lassitude, bleeding, chills and fever, bruise, muscle tension, and some dark blue signs like black rim of eyes [3], women's blood stasis mostly for gynecology diseases for instance of dysmenorrhea, menoxenia, uterine fibroids in clinic [4].

The drug pair of Typhae Pollen and Trogopterus Feces which we named it for Shixiao San originally came from the Classified Materia Medica in volume twenty-two jinxiao fang, which was written by Shen-wei Tang in Song dynasty of ancient china [5]. As described in early publications, Typhae Pollen-Trogopterus Feces drug pair is famous for its remarkable and reliable therapeutic actions in a multitude diseases caused by blood stasis such as hyperlipidemia, atherosclerosis, thrombosis, stroke, angina pectoris and gynecological diseases by means of promoting blood circulation and removing stasis [6-8]. Typhae Pollen, known as Puhuang in Chinese is the dry pollen of typhaceae plant Typha angustifolia L., Typha orientalis Presl., and all species of the genus Typha [9]. Recent pharmacological study indicated that Typhae Pollen is proved to possess quite a few of biological activities including inducing uterine contractions, antioxidant, anti-inflammation, wound healing, and etc. [10-12], which owes to the main active ingredients among them like flavonoids, steroids, fatty acids, etc. [13]. Typhaneoside, vanillic acid and $p$-coumaric acid are just the three major bioactive components consist in Typhae Pollen due to their high content and significant bioactivities. Trogopterus feces also called Wulingzhi originally recorded in the Kaibao Bencao, and it is the dry feces of Trogopterus xanthipes Milne-Edwards (Petauristidae) [14]. It has been reported that the main chemical constituents including terpenoids [15], phenolic acids, sterols, aliphatics, fatty acids, and flavonoids are commonly used in the inhibition of tumor formation, inducing tumor cell apoptosis, antioxidant, reducing antithrombin levels, cytotoxic activity, immunity enhancement, anti-inflammatory activities, etc. $[16,17]$.

Drug pair, as is less known at abroad, it is the unique combination of two relatively fixed drugs based on theory of TCM in clinic, which nowadays have played a key role increasingly in the development of TCM and captured researcher's attention for the most fundamental and the simplest form of Chinese drug formulae [18, 19]. As the basic composition units of Chinese drug compatibility, reducing the toxicity and increasing the efficacy of drugs are supposed to be the basis of its efficiency [20]. With an increasing number of researches on drug pairs, works about the possible modes of actions for some famous pairs have obtained a certain achievement, just like Danggui Buxue Decoction (Astragali Radix and Angelicae sinensis Radix) [21] and TaorenHonghua (Persicae Semen and Carthami Flos) herb pair [22]. More recent study suggested that how the synergistic effects of drug pairs come into being not only by changing the constitution or content of bioactive compounds but also regulating its absorption, distribution, metabolism and excretion (ADME) [23, 24].

According to the previous report, there are numerous studies about Typhae Pollen-Trogopterus Feces drug pair in each aspect while hardly any about the compatibility mechanism of it. Here, based on our early investigations $[25,26]$, the ultra-performance liquid chromatography coupled with a triple quadrupole electrospray tandem mass spectrometry (UPLC-TQ/MS) method has been performed to compare the pharmacokinetic profile of three major bioactive components including typhaneoside, vanillic acid and $p$-coumaric acid among Typhae PollenTrogopterus Feces drug pair before and after compatibility. Achievements of this study were desired to provide beneficial scientific information for revealing the reasonable compatibility of this drug pair and better understanding about its in vivo behavior mechanism.

\section{Methods}

\section{Chemicals, reagents and materials}

The reference standards of typhaneoside (111573200603), vanillic acid (110776-200602), p-coumaric acid (D-032-120603) and diphenhydramine hydrochloride as internal standards (IS, 130356-200503) were purchased from the National Institute for the Control of Pharmaceutical and Biological Products (Beijing, China), the chemical structures of them are showed in Fig. 1.

Acetonitrile and methanol were of HPLC grade and obtained from Jiangsu Hanbon Science and Technology Co., Ltd. (China) and Tedia (Fairfield, USA), respectively. Formic acid was analytical grade from Merck (Darmstadt, Germany). Ultra-pure water was purified by an EPED super purification system (China). All other reagents were of analytical grade.

Typhae Pollen and Trogopterus Feces were purchased from Nanjing Chinese and Western Pharmaceutical Co., Ltd., and authenticated by the corresponding author. They were within the qualitative and quantitative stipulation of Chinese Pharmacopoeia. The voucher specimens (No.NJUTCM-20090118 for Typhae Pollen and No.NJUTCM-20090119 for Trogopterus Feces) were 
<smiles>COc1cc(-c2oc3cc(O)cc(O)c3c(=O)c2OC2O[C@H](CO[C@@H]3O[C@H](C)[C@@H](O)[C@H](O)[C@H]3O)[C@@H](O)[C@H](O)[C@H]2O[C@@H]2O[C@H](C)[C@@H](O)[C@H](O)[C@H]2O)ccc1O</smiles>

A<smiles>COc1cc(C(=O)O)ccc1O</smiles>

B<smiles>O=C(O)c1ccc(O)cc1</smiles>

$\mathrm{C}$

Fig. 1 Chemical structures of the reference substances (A. typhaneoside; B. vanillic acid; C. p-coumaric acid)

deposited at the herbarium in Nanjing University of Chinese Medicine, China.

\section{Apparatus and UPLC-TQ/MS conditions} ACQUITY $^{\mathrm{TM}}$ UPLC system, XevoTM TQ mass spectrometry system (Waters Corp., Milford, MA, USA); EPED ultrapure water machine (Nanjing, China); Sartorius BT1250 electronic balance (Sartorius Scientific Instruments Corporation, Beijing, China); CENTRIVAP centrifuge enrichment apparatus (Labconco); ML303 electronic balance (Mettler Toledo Instruments Co., Ltd. Shanghai, China); TDL-80-2B centrifuge (Beckman Coulter, Inc.).

An ACQUITY UPLC BEH $\mathrm{C}_{18}$ column $(2.1 \mathrm{~mm} \times$ $100 \mathrm{~mm}, 1.7 \mu \mathrm{m}$, Waters Corp., Milford, MA, USA) was applied and the column temperature was maintained at $35{ }^{\circ} \mathrm{C}$. The mobile phase was composed of $\mathrm{A}(0.1 \%$ aqueous formic acid) and $\mathrm{B}$ (acetonitrile) using a gradient elution of $5-10 \%$ B at $0-1 \mathrm{~min}, 10-30 \% \mathrm{~B}$ at $1-6 \mathrm{~min}, 30-$ $40 \% \mathrm{~B}$ at $6-7 \mathrm{~min}, 40-95 \% \mathrm{~B}$ at $7-8 \mathrm{~min}, 95-5 \% \mathrm{~B}$ at 8-9 min, $95 \% \mathrm{~B}$ at $9-10 \mathrm{~min}$ with a flow rate set at $0.4 \mathrm{~mL} / \mathrm{min}$. The auto-sampler was conditioned at $4{ }^{\circ} \mathrm{C}$ and the injection volume was $5 \mu \mathrm{L}$.

Mass spectrometry detection was performed by using a Xevo Triple Quadrupole MS (Waters Corp., Milford, MA) equipped with an electrospray ionization source (ESI). The ESI source was set in positive ionization mode. The scanning mode was set multiple reaction monitoring (MRM) mode. Parameters set in the source were as follows: the capillary voltage at $1 \mathrm{kV}$; sampling cone voltage of $30 \mathrm{~V}$; source temperature $15^{\circ} \mathrm{C}$; desolvation temperature $550{ }^{\circ} \mathrm{C}$; dwell time was automatically set by MassLynx (Waters Corp., Milford, MA, USA). The cone voltage and collision energy optimized for each analyte and selected values are given in Table 1.

\section{Preparation of calibration standards and quality control} (QC) samples

The mixture of standard stock solution containing above three compounds were prepared in methanol and giving a final concentrations of $28.2 \mu \mathrm{g} / \mathrm{mL}$ for typhaneoside, $25.7 \mu \mathrm{g} / \mathrm{mL}$ for vanillic acid, and $26.5 \mu \mathrm{g} / \mathrm{mL}$ for $p$-coumaric acid, respectively. The mixture stock solution was serially diluted with methanol to provide working standard solutions of desired concentration of $0.282 \mathrm{mg} / \mathrm{mL}$ for typhaneoside, $0.257 \mathrm{mg} / \mathrm{mL}$ for vanillic acid, and $0.265 \mathrm{mg} / \mathrm{mL}$ for $p$-coumaric acid, respectively. The IS stock solution were also prepared in methanol for diphenhydramine hydrochloride (IS) of $1.04 \mu \mathrm{g} / \mathrm{mL}$.

Calibration standards and quality control (QC) samples were prepared as following: the mixture of standard working solution was diluted into eight different concentration gradients, and given the final concentration of $0.142 \sim 7100 \mathrm{ng} / \mathrm{mL}$ for typhaneoside, $0.104 \sim 5200 \mathrm{ng} /$ $\mathrm{mL}$ for vanillic acid, $0.102 \sim 5100 \mathrm{ng} / \mathrm{mL}$ for $\mathrm{p}$-coumaric acid. Quality control (QC) samples at low, middle and high concentrations were $3.55,71.0,710 \mathrm{ng} / \mathrm{mL}$ for typhaneoside, $2.60,52.0,260 \mathrm{ng} / \mathrm{mL}$ for vanillic acid and 2.55, 51.0, $255 \mathrm{ng} / \mathrm{mL}$ for p-coumaric acid. All solutions were stored at $4{ }^{\circ} \mathrm{C}$ and brought to room temperature before use. QC samples were stored at $-20{ }^{\circ} \mathrm{C}$ before analysis.

\section{Preparation of drug extraction and sample solutions}

The raw materials of Typhae Pollen $(200 \mathrm{~g})$ for single extract and Typhae Pollen-Trogopterus Feces (200 g + $200 \mathrm{~g}$ ) for co-decoction (two drugs decoct together) and mixed decoction (two drugs decoct separately and then mix) was accurately weighed, extracted with boiling 
Table 1 The optimum mass spectrometry conditions for three compounds and IS

\begin{tabular}{|c|c|c|c|c|}
\hline Analytes & Ionizationmode & MRM transitions (precursor-product) & $\begin{array}{l}\text { Cone voltage } \\
\text { (V) }\end{array}$ & Collision energy (eV) \\
\hline Typhaneoside & $\mathrm{ES}^{+}$ & $771.0319 \rightarrow 317.0719$ & 18 & 26 \\
\hline Vanillic Acid & $\mathrm{ES}^{+}$ & $168.8404 \rightarrow 65.1300$ & 16 & 20 \\
\hline P-coumaric Acid & $\mathrm{ES}^{+}$ & $164.8404 \rightarrow 91.0910$ & 16 & 26 \\
\hline Diphenhydramine Hydrochloride & $\mathrm{ES}^{+}$ & $256.2127 \rightarrow 167.1291$ & 12 & 16 \\
\hline
\end{tabular}

water (1:10) for $2 \mathrm{~h}$, and then extracted with boiling water $(1: 8)$ for $2 \mathrm{~h}$. The filtrates were combined and solvent was removed under reduced pressure in a rotary evaporator to reach a certain volume at the ratio of 1:1 (w/w, weight of all constituting drugs and the extract filtrates) for the TP single drug extraction; 2:1 for the TPTF co-decoction and TP-TF mixed decoction. The contents of three compounds measured quantitatively by UPLC were $167.73,168.37,153.32 \mu \mathrm{g} / \mathrm{mL}$ for typhaneoside; $51.83,48.67,45.02 \mu \mathrm{g} / \mathrm{mL}$ for vanillic acid and $36.62,35.67,33.12 \mu \mathrm{g} / \mathrm{mL}$ for $p$-coumaric acid in single extract, co-decoction and mixed decoction, respectively.

A $200 \mu \mathrm{L}$ aliquot of plasma sample was added with $10 \mu \mathrm{L}$ diphenhydramine hydrochloride working solution and $600 \mu \mathrm{L}$ of methanol. After vortex for $2 \mathrm{~min}$ and centrifugation at $13,000 \mathrm{rpm}$ for $10 \mathrm{~min}$, the supernatant was transferred to another $1.5 \mathrm{~mL}$ tube and concentrated in the centrifuge enrichment apparatus at $37^{\circ} \mathrm{C}$.

Finally, each residue was reconstituted in $200 \mu \mathrm{L} 70 \%$ methanol, then vortexed for $3 \mathrm{~min}$ and centrifuged at
$13,000 \mathrm{rpm}$ for $10 \mathrm{~min} .5 \mu \mathrm{L}$ of supernatant was injected into the UPLC-TQ/MS system for analysis.

\section{Validation of the HPLC method Specificity, linearity and LLOQ}

The specificity of the method was evaluated by comparing chromatograms of blank plasma sample, blank plasma sample spiked with reference standards and internal standards, and plasma sample after oral administration of Typhae Pollen-Trogopterus Feces co-decoction for $30 \mathrm{~min}$.

The linearity of each calibration curve was determined by plotting the peak area ratio (Y) of analytes to corresponding IS versus the nominal concentration $(\mathrm{X})$ of analytes with weighted $\left(1 / X^{2}\right)$ least square linear regression. The lower limit of quantification (LLOQ) was determined as the lowest concentration with a signal-to-noise $(\mathrm{S} / \mathrm{N})$ ratio of 10 .

\section{Precision and accuracy}

Accuracy and intra- and inter-day precision of the established method were evaluated by QC samples at low, medium and high concentrations (six samples for each)

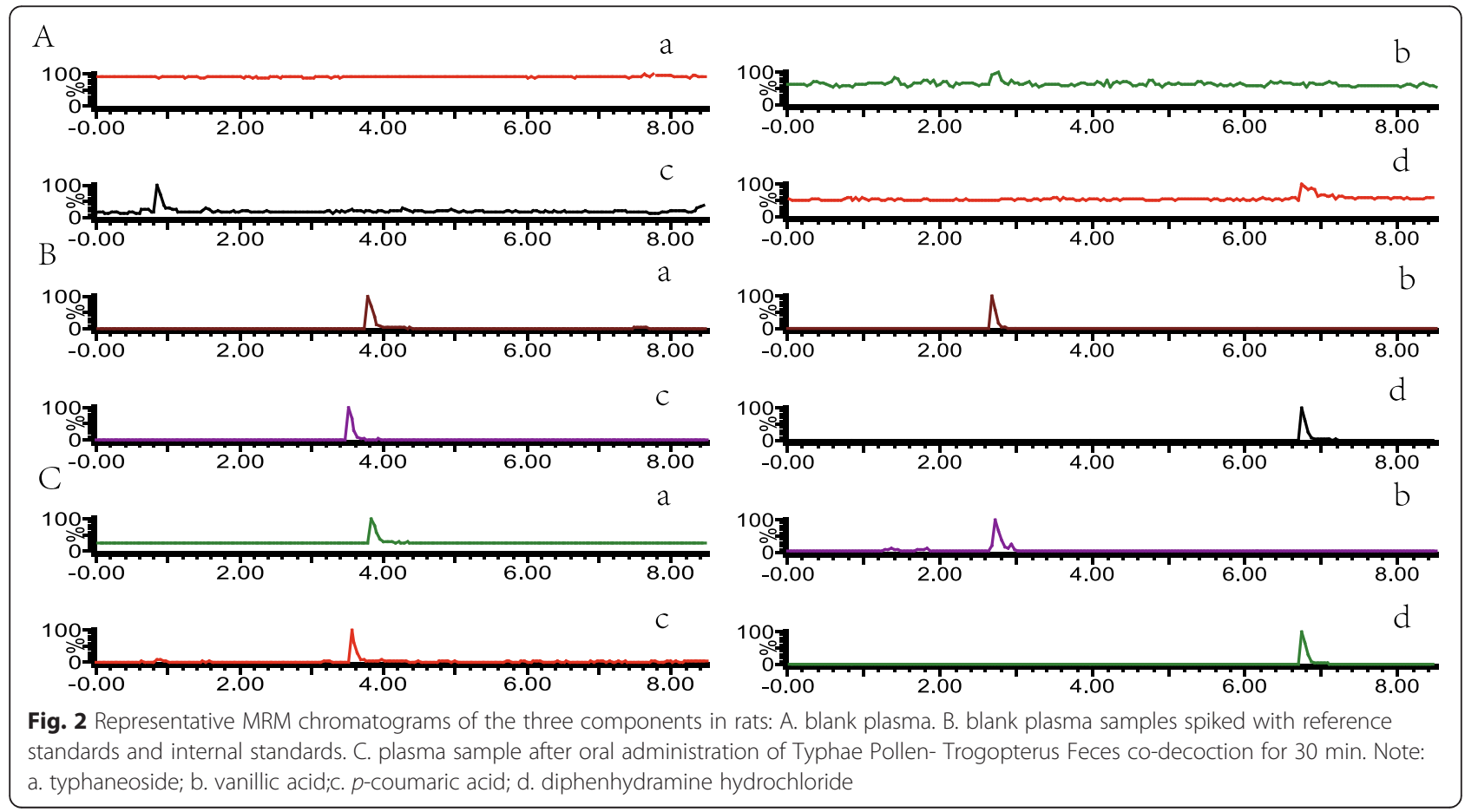




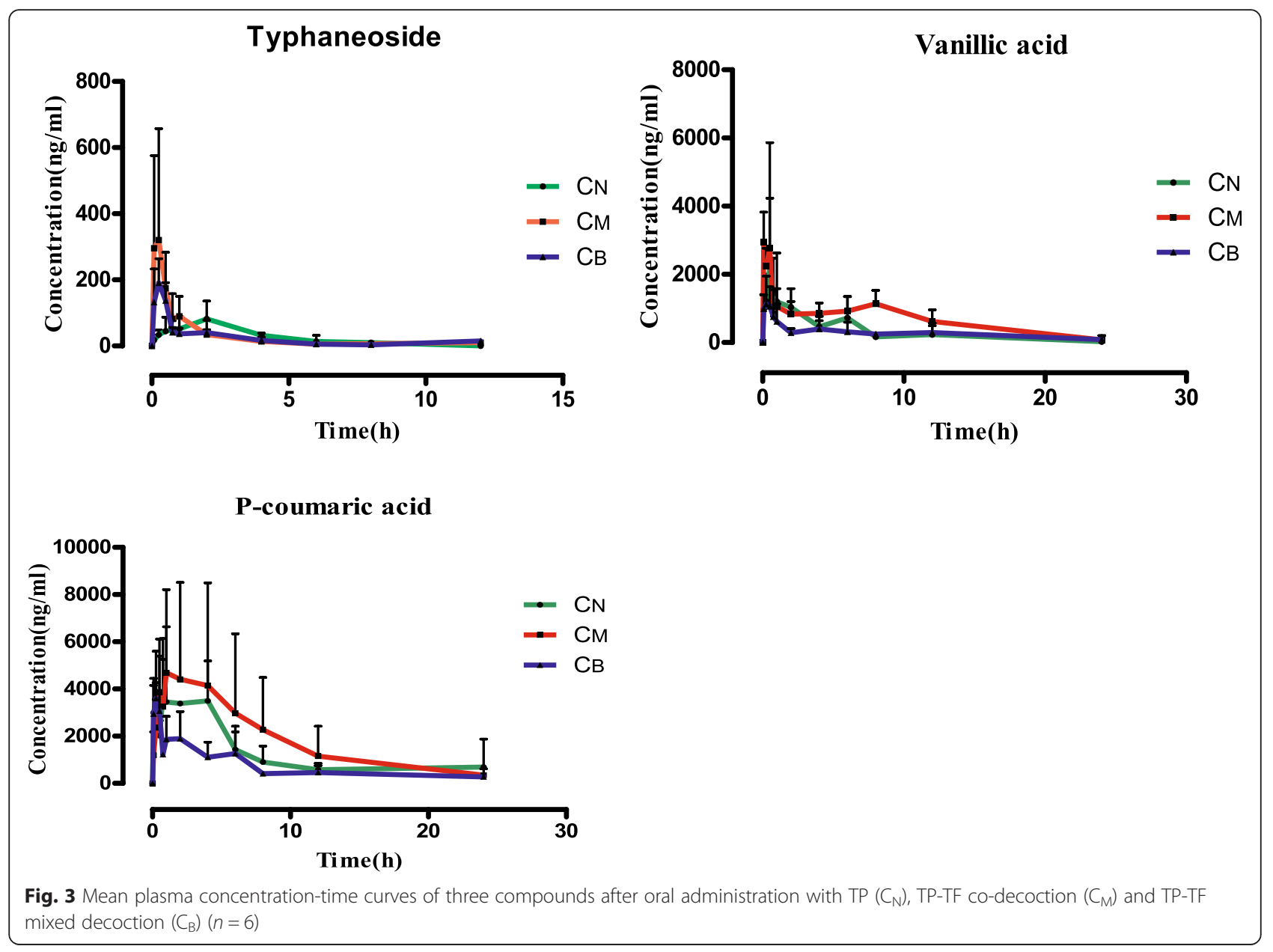

on 3 consecutive validation days. The precision expressed by relative standard deviation (RSD\%), and the accuracy by relative percentage error (\%).

\section{Extraction recovery, matrix effect and stability}

The extraction recoveries of analytes were determined by comparing the peak responses of three QC samples (six samples for each) in the post-extraction spiked samples to that acquired from pre-extraction spiked samples at equivalent concentrations. The matrix effect was evaluated by comparing the peak responses of samples where the extracted matrix was spiked with standard solutions to those obtained from neat standard solutions at equivalent concentrations.

The stability of the analytes in rat plasma was assessed by analyzing QC samples at three concentration levels (six samples for each) under different condition. Three QC samples were tested for pre-treatment, posttreatment and three freeze-thaw cycles at room temperature for $12 \mathrm{~h}$, refrigerated $\left(4^{\circ} \mathrm{C}\right)$ for $24 \mathrm{~h}$ and repeatedly frozen and thawed for three times at $-80{ }^{\circ} \mathrm{C}$, respectively.

\section{Pharmacokinetic studies}

All experiments were performed on female SpragueDawley (SD) rats, weighing 220-250 g, obtained from Shanghai Slac Laboratory Animal Co., Ltd. (Shanghai, China). They were kept in plastic cages at $22 \pm 2{ }^{\circ} \mathrm{C}$ and a relative humidity of 50-65\%, with free access to pellet food and water on a $12 \mathrm{~h}$ light/dark cycle. Animal welfare and experimental procedures strictly conformed to the Guide for the Care and Use of Laboratory Animals [27] and the related ethics regulations of Nanjing University of Chinese Medicine.

For pharmacokinetic studies, the SD rats were divided into four groups randomly ( $n=6$ per group), and housed with unlimited access to food before the experiment while water available. Each group except the control group was oral administration of TP $\left(\mathrm{C}_{\mathrm{N}}\right)$ single drug decoction, TP-TF co-decoction $\left(\mathrm{C}_{\mathrm{M}}\right)$ and TP-TF mixed decoction $\left(C_{B}\right)$ at a dosage of $5 \mathrm{~g} / \mathrm{kg}, 10 \mathrm{~g} / \mathrm{kg}, 10 \mathrm{~g} / \mathrm{kg}$ body weight, respectively. Blood samples $(0.5 \mathrm{~mL})$ were collected at certain time points and placed at a $1.5 \mathrm{~mL}$ tube before oral $(0 \mathrm{~min})$ and after oral $(5,15,30,45,60$, 120, 240, 360, 480, 720 and $1440 \mathrm{~min}$ ) administration. Afterwards all the blood samples were centrifuged at 
$13,000 \mathrm{rpm}$ for $10 \mathrm{~min}$ and stored at $-80{ }^{\circ} \mathrm{C}$ until analysis.

\section{Results and discussion}

\section{Validation of the quantitative analysis}

Fig. 2 shows the typical MRM chromatograms of blank plasma sample, blank plasma sample spiked with reference standards and internal standards, and plasma sample after oral administration of Typhae PollenTrogopterus Feces co-decoction for $30 \mathrm{~min}$. No interference peaks were observed at the retention times of analytes and IS in any plasma that used for analysis, the method presented good specificity.

The linear regression equation, correlation coefficient and LLOQ for typhaneoside, vanillic acid and pcoumaric acid in rat plasma samples are shown in Additional file 1. The calibration curves exhibited good linearity with correlation coefficients (r) and the LLOQ were sufficient for pharmacokinetic studies of these analytes.

Intra-day, inter-day accuracy and precision of the three compounds in rat plasma samples are presented in Additional file 2, which showed the method with good accuracy and precision. All the results were found to be within the accepted variable limits.

Extraction recoveries and matrix effect of the three compounds were evaluated by analyzing QC samples at low, medium and high concentrations with six replicates. As the results are shown in Additional file 3, the mean recovery of the analytes was within 70 to $91 \%$ (RSD was less than 11). The corresponding matrix effect ranged from 76 to $106 \%$ (RSD was less than 9).

The stability of the analytes in rat plasma samples was evaluated under different conditions. Deviations for the peak area of the three components were within $15 \%$, which indicated good stability under the experimental conditions.

\section{Pharmacokinetic study}

The mean plasma concentration-time profiles of typhaneoside, vanillic acid and $p$-coumaric acid were determined after oral administration with different compatibility of Typhae Pollen-Trogopterus Feces drug pair in rats, the concentration-time curves are presents in Fig. 3, and the noncompartment model pharmacokinetic parameters including maximum plasma concentration $\left(\mathrm{C}_{\max }\right)$, time to reach the maximum concentrations $\left(\mathrm{T}_{\max }\right)$, half-time $\left(\mathrm{T}_{1 / 2}\right)$, area under concentration-time curve (AUC $\left.0 \sim \mathrm{t}\right)$ are summarized in Table 2.

From the datas, it indicated that typhaneoside, vanillic acid and $p$-coumaric acid could be detected immediately by UPLC-TQ/MS, which revealed superior absorption of the three compounds, and significant differences existed among three different compatibilities, all comparing to the control group with TP single drug extraction by $t$-test. For typhaneoside, the peak plasma concentration $\left(\mathrm{C}_{\max }\right)$ was $370.86 \pm 315.71 \mathrm{ng} / \mathrm{mL}(P<0.05)$ in TP-TF co-decoction group $\left(\mathrm{C}_{\mathrm{M}}\right)$ and $214.32 \pm 73.72 \mathrm{ng} / \mathrm{mL}(P<0.01)$ in TP-TF mixed decoction group $\left(C_{B}\right)$, it was significantly higher than TP single drug extraction $\left(\mathrm{C}_{\mathrm{N}}\right)$, though in the previous report it was described as a low bioavailability [28]. What's more, the time to reach maximum concentrations $\left(\mathrm{T}_{\max }\right)$ were $0.24 \pm 0.15 \mathrm{~h}(P<0.05)$ for TP-TF codecoction group $\left(C_{M}\right)$ and $0.21 \pm 0.08 \mathrm{~h}$ for TP-TF mixed decoction group $\left(C_{B}\right)$, which implies highly uptake of this compound in rats plasma.

As a kind of common compound in many Chinese medicines, vanillic acid in TP-TF co-decoction group $\left(\mathrm{C}_{\mathrm{M}}\right)$ had a good absorption after oral administration for the $\mathrm{C}_{\max }$ was $3870.99 \pm 2527.99 \mathrm{ng} / \mathrm{mL}$ and $\mathrm{T}_{\max }$ was $1.47 \pm 3.20 \mathrm{~h}$. In TP-TF mixed decoction group $\left(C_{B}\right)$ the

Table 2 Noncompartment model pharmacokinetic parameters of the three compounds after oral administration with extracts $(n=6)$

\begin{tabular}{|c|c|c|c|c|}
\hline Compounds & Pharmacokinetic parameters & $\mathrm{TP}$ & TP-TF co-decoction & TP-TF mixed decoction \\
\hline \multirow[t]{4}{*}{ Typhaneoside } & $C_{\max }(\mathrm{ng} / \mathrm{mL})$ & $76.39 \pm 53.21$ & $370.86 \pm 315.71^{*}$ & $214.32 \pm 73.72^{* *}$ \\
\hline & $\mathrm{T}_{\max }(\mathrm{h})$ & $2.95 \pm 2.88$ & $0.24 \pm 0.15^{*}$ & $0.21 \pm 0.08$ \\
\hline & $\mathrm{T}_{1 / 2}(\mathrm{~h})$ & $3.35 \pm 2.58$ & $1.91 \pm 1.26$ & $1.37 \pm 0.54$ \\
\hline & $\mathrm{AUC}_{0 \sim \mathrm{t}}(\mathrm{ng} / \mathrm{h} / \mathrm{mL})$ & $268.31 \pm 167.71$ & $333.46 \pm 191.84$ & $275.62 \pm 206.06$ \\
\hline \multirow[t]{4}{*}{ Vanillic acid } & $C_{\max }(n g / m L)$ & $2211.68 \pm 1187.17$ & $3870.99 \pm 2527.99$ & $1447.29 \pm 500.99$ \\
\hline & $\mathrm{T}_{\max }(\mathrm{h})$ & $1.25 \pm 0.71$ & $1.47 \pm 3.20$ & $0.17 \pm 0.09^{* *}$ \\
\hline & $\mathrm{T}_{1 / 2}(\mathrm{~h})$ & $3.69 \pm 0.87$ & $11.25 \pm 13.61$ & $8.88 \pm 3.76$ \\
\hline & $A \cup C_{0 \sim t}(n g / h / m L)$ & $10445.53 \pm 4148.68$ & $14137.57 \pm 4540.37$ & $6193.78 \pm 4499.17$ \\
\hline \multirow[t]{4}{*}{ P-coumaric acid } & $C_{\max }(\mathrm{ng} / \mathrm{mL})$ & $4901.39 \pm 1887.30$ & $5110.22 \pm 3671.26$ & $4189.45 \pm 844.37$ \\
\hline & $\mathrm{T}_{\max }(\mathrm{h})$ & $1.08 \pm 1.67$ & $1.42 \pm 1.39$ & $0.46 \pm 0.40$ \\
\hline & $\mathrm{T}_{1 / 2}(\mathrm{~h})$ & $3.67 \pm 1.82$ & $10.08 \pm 7.86$ & $10.08 \pm 10.23$ \\
\hline & $\mathrm{AUC}_{0 \sim \mathrm{t}}(\mathrm{ng} / \mathrm{h} / \mathrm{mL})$ & $36881.01 \pm 25783.25$ & $41512.56 \pm 41763.28$ & $17689.11 \pm 3882.21$ \\
\hline
\end{tabular}

${ }^{*} P<0.05,{ }^{* *} P<0.01$ versus TP sole administration 
$C_{\max }$ was $1447.29 \pm 500.99 \mathrm{ng} / \mathrm{mL}$ and $\mathrm{T}_{\max } 0.17 \pm$ $0.09 \mathrm{~h}(P<0.01)$. In addition, it is not difficult to find that $\mathrm{T}_{\max }$ and $\mathrm{T}_{1 / 2}$ in co-decoction group $\left(\mathrm{C}_{\mathrm{M}}\right)$ were longer than the two others, and double peak phenomenon was observed at the same time, it probably attribute to the enterohepatic circulation in drug metabolism or the interactivity in Typhae pollen-Trogopterus Feces drug pair. Similarly as vanillic acid, $p$-coumaric acid was also absorbed well, $C_{\max }$ was $5110.22 \pm 3671.26 \mathrm{ng} / \mathrm{mL}$ in TP-TF co-decoction group $\left(C_{M}\right)$ in addition to its $T_{\max }$ was somewhat longer. It may be in virtue of its hydrolyzed diffusion in vivo after oral administration with decoction [29], and we can see double peaks clearly on the concentration-time curves, all these hypothesis need further investigations.

When making comparison between TP-TF codecoction group $\left(\mathrm{C}_{\mathrm{M}}\right)$ and TP-TF mixed decoction group $\left(C_{B}\right), C_{\max }$ and $A C_{0 \sim t}$ of the three active ingredients in TP-TF co-decoction group $\left(\mathrm{C}_{\mathrm{M}}\right)$ are higher than TP-TF mixed decoction group $\left(C_{B}\right)$. It proved that the absorption was increased after compatibility and the duration of drug action was prolonged for $T_{1 / 2}$ of the three compounds in TP-TF co-decoction group $\left(\mathrm{C}_{\mathrm{M}}\right)$ were longer than TP-TF mixed decoction group $\left(\mathrm{C}_{\mathrm{B}}\right)$. Generally speaking, the TP-TF co-decoction group $\left(C_{M}\right)$ showed more advantages of bioavailability for bioactive components.

The results indicated that after Typhae Pollen and Trogopterus Feces used in combination as a drug pair, the three bioactive compounds typhaneoside, vanillic acid and $p$-coumaric acid were well absorbed and slowly eliminated in rats, thus to enhance and prolong clinical efficacy, which may be due to the synergic action between Typhae Pollen and Trogopterus Feces. According to traditional Chinese medicine theory, the compatibility mechanisms of drug pairs are not only arbitrary plus of two drugs but also the regularity of active components in vivo [30]. When Typhae Pollen combined with Trogopterus Feces, the dissolution of chemical ingredients were increased [31], followed by the good absorption of three components in TP. We speculated that it's probably the volatile components in TF which enhanced the absorption of the three components in TP [32, 33]. Furthermore the higher uptake and slower elimination of three compounds in TP by drug pair administration were related to the interaction between drugs mediated by transport proteins, metabolic enzymes, or plasma protein binding, etc. The compatibility mechanism of TP-TF still deserves further research.

\section{Conclusion}

In this paper, the simple, rapid and sensitive UPLC-TQ/MS method was successfully applied to detect three bioactive components in Typhae Pollen before and after the combination with Trogopterus Feces simultaneously. It was the first study to report about the pharmacokinetic parameters of typhaneoside, vanillic acid and $p$-coumaric acid in TP-TF after oral administration. Results indicated that the three compounds have better absorption and slower elimination after Typhae Pollen and Trogopterus Feces combination. The in vivo changes of three main active substances was helpful for finding the compatibility principles of TPTF and clarifying its rational compatibility, thus for better clinical application and research about relative TCM formulas.

\section{Additional files}

Additional file 1: The regression equations, correlation coefficient, linear ranges and LLOQ of three analytes $(\boldsymbol{n}=6)$. (DOC $21 \mathrm{~kb}$ )

Additional file 2: Intra-day, inter-day accuracy and precision of three analytes $(\boldsymbol{n}=6)$. (DOC $21 \mathrm{~kb})$

Additional file 3: Recoveries and matrix effects of three analytes $(\boldsymbol{n}=\mathbf{6})$. (DOC $21 \mathrm{~kb})$

\section{Abbreviations}

TP: Typhae Pollen; TF: Trogopterus Feces; $C_{N}$ : TP single extract group; $C_{M}$ : TP-TF co-decoction group; $\mathrm{C}_{\mathrm{B}}$ : TP-TF mixed decoction group; BS: Blood stasis; TCM: Traditional Chinese Medicine; ADME: Absorption, distribution, metabolism and excretion; UPLC-TQ/MS: Ultra-performance liquid chromatography coupled with a triple quadrupole electrospray tandem mass spectrometry;

ESI: Electrospray ionization source; MRM: Multiple reaction monitoring; QC: Quality control; LLOQ: Lower limit of quantification; SD: Sprague-Dawley.

\section{Competing interests}

The authors declare that they have no competing interest.

\section{Authors' contribution}

HTZ performed the experiments, analyzed the data and drafted the manuscript. PX, XCH and JMG assisted in carrying out experiments. JAD, YPT and SLS participated in the conception and design of the study. EXS and DWQ performed the statistical analysis and revised the manuscript. All authors read and approved the final version of the manuscript.

\section{Acknowledgements}

This work was supported by the Key Research Project in Basic Science of Jiangsu College and University (No. 11KJA360002; 12KJA360002) and the National Natural Science Foundation of China (No. 81373889; 81102898; 81102885). This work was also supported by the Construction Project for Jiangsu Key Laboratory for High Technology Research of TCM Formulae (BM2010576; BK2010561), and supported by Program for Excellent Talents in School of Pharmacy of Nanjing University of Chinese Medicine (15ZYXET-2), and a project funded by the Priority Academic Program Development of Jiangsu Higher Education Institutions (ysxk-2014) and the Construction Project for Jiangsu Collaborative Innovation Center of Chinese Medicinal Resources Industrialization. This work was also supported by 2013 Program for New Century Excellent Talents by the Ministry of Education (Grant NCET13-0873), 333 High-level Talents Training Project Funded by Jiangsu Province, and Six Talents Project Funded by Jiangsu Province (2012-YY-010).

\section{Author details}

${ }^{1}$ Jiangsu Key Laboratory for High Technology Research of TCM Formulae, Nanjing University of Chinese Medicine, Nanjing 210023, China. ${ }^{2}$ Jiangsu Collaborative Innovation Center of Chinese Medicinal Resources Industrialization, Nanjing University of Chinese Medicine, Nanjing 210023, China. ${ }^{3}$ National and Local Collaborative Engineering Center of Chinese Medicinal Resources Industrialization and Formulae Innovative Medicine, Nanjing University of Chinese Medicine, Nanjing 210023, China. ${ }^{4}$ Jiangsu Key 
Laboratory for TCM Formulae Research, Nanjing University of Chinese Medicine, Nanjing 210046, People's Republic of China.

Received: 25 November 2015 Accepted: 6 January 2016 Published online: 20 January 2016

\section{References}

1. Park B, Yun KJ, Jung J, You S, Lee JA, Choi J, et al. Conceptualization and utilization of blood stasis syndrome among doctors of Korean medicine: results of a web-based survey. Am J Eransl Res. 2014;6(6):857-68.

2. Zhao XJ, Zhang Y, Meng XL, Yin PY, Deng C, Chen J, et al. Effect of a traditional Chinese medicine preparation Xindi soft capsule on rat model of acute blood stasis: a urinary metabonomics study based onliquid chromatography-mass spectrometry. J Chromatogr B. 2008;873(2):151-8.

3. Park YJ, Yang DH, Lee JM, Park YB. Development of a valid and reliable blood stasis questionnaire and its relationship to heart rate variability. Complement Ther Med. 2013;21(6):633-40.

4. Su SL, Cui WX, Duan JA, Hua YQ, Guo JM, Shang EX, et al. UHPLC-MS Simultaneous determination and pharmacokinetic study of three aromatic acids and one monoterpene in rat plasma after oral administration of Shaofu Zhuyu Decoction. Am J Chin Med. 2013;41(3):697-715.

5. Zhou W, Su SL, Duan JA, Tao WW. The association analysis of shixiaosan's traditional utility and modern research. Chin Trad Plant Med. 2009;31(10):1602-4.

6. Zhang $\mathrm{P}$, Xia XH, Li Q. The effects of anti-thrombosis and thrombolysis of diferent solvent extract of shixiaosan. China Pharm. 2003;12(3):44-5.

7. Wang XF, Zhao X, Gu LQ, Zhang YY, Bi KS, Chen XH. Discrimination of aqueous and vinegary extracts of Shixiao San using metabolomics coupled with multivariate data analysis and evaluation of anti-hyperlipidemic effect. Asi J Pharm Sci. 2014:9(1):17-26.

8. Zhou W, Su SL, Liu P, Hua YQ, Duan JA. Effects of promoting blood circulation to remove blood stasis of Puhuang-Wulingzhi drug pair in Shaofu Zhuyu Decoction. Chin J Exp Tradit Med Form. 2010;16(6):179-83.

9. Chen PD, Liu SJ, Dai GL, Xie LY, Xu J, Zhou L, et al. Determination of typhaneoside in rat plasma by liquid chromatography-tandem mass spectrometry. J Pharm Biomed Anal. 2012;70:636-9.

10. Lee BC, Park HM, Sims HS, Kim GS, Gu SH, Oh MJ. Biological activity and chemical analysis of cattail pollens. J Agric Sci. 2009;36(2):185-97.

11. Sun $B$, Sun $G B$, Xiao J, Chen RC, Wang $X, W u$ Y, et al. Isorhamnetin inhibits $\mathrm{H}_{2} \mathrm{O}_{2}$-induced activation of the intrinsic apoptotic pathway in $\mathrm{H} 9 \mathrm{c} 2$ cardiomyocytes through scavenging reactive oxygen species and ERK inactivation. J Cell Biochem. 2012;113(2):473-85.

12. Peterson JJ, Dwyer JT, Jacques PF, McCullough ML. Associations between flavonoids and cardiovascular disease incidence or mortality in European and US populations. Nutr Rev. 2012;70(9):491-508.

13. Gallardo-Williams MT, Geiger CL, Pidala JA, Martin DF. Essential fatty acids and phenolic acids from extracts and leachates of southern cattail (Typha domingensis P.). Phytochemistry. 2002;59(3):305-8.

14. Yang NY, Tao WW, Zhu M, Duan JA, Zhang JG. Two new isopimarane diterpenes from the feces of Trogopterus xanthipes. Fitoterapia. 2010;81(5):381-4.

15. Zhao J, Zhu HJ, Zhou XJ, Yang TH, Wang YY, Su J, et al. Diterpenoids from the feces of Trogopterus xanthipes. J Nat Prod. 2010;73(5):865-9.

16. Yang NY, Tao WW, Duan JA. Antithrombotic flavonoids from the faeces of Trogopterus xanthipes. Nat Prod Res. 2010;24(19):1843-9.

17. Baek S, Xia X, Min BS, Park C, Shim SH. Trogopterins A-C: Three new neolignans from feces of Trogopterus xanthipes. Beilstein J Org Chem. 2014;10:2955-62.

18. Wang SP, Hu YY, Tan W, Wu X, Chen RE, Cao JL, et al. Compatibility art of traditional Chinese medicine: From the perspective of herb pairs. J Ethnopharmacol. 2012;143(2):412-23.

19. Guo YP, Lin LG, Wang YT. Chemistry and pharmacology of the herb pair Flos Lonicerae japonicae-Forsythiae fructus. Chin Med. 2015;10:16.

20. Chen L, Yang J, Davey AK, Chen YX, Wang JP, Liu XQ. Effects of diammonium glycyrrhizinate on the pharmacokinetics of aconitine in rats and the potential mechanism. Xenobiotica. 2009:39(12):955-63.

21. Shi XQ, Tang YP, Zhu HX, Li WX, Li ZH, Li W, et al. Comparative tissue distribution profiles of five major bioactive components in normal and blood deficiency rats after oral administration of Danggui Buxue Decoction by UPLC-TQ/MS. J Pharm Biomed Anal. 2014;88:207-15.

22. Liu L, Duan JA, Tang YP, Guo JM, Yang NY, Ma HY, et al. Taoren-Honghua herb pair and its main components promoting blood circulation through influencing on hemorheology, plasma coagulation and platelet aggregation. J Ethnopharmacol. 2012;139(2):381-7.
23. Gilbert B, Alves LF. Synergy in plant medicines. Curr Med Chem. 2003;10(1):13-20.

24. Ung CY, Li H, Cao ZW, Li YX, Chen YZ. Are herb-pairs of traditional Chinese medicine distinguishable from others? Pattern analysis and artificial intelligence classification study of traditionally defined herbal properties. J Ethnopharmacol. 2007;111(2):371-7.

25. Su SL, Hua YQ, Duan JA, Zhou W, Shang EX, Tang YP. Inhibitory effects of active fraction and its main components of Shaofu Zhuyu Decoction on uterus contraction. Am J Chin Med. 2010;38(4):777-87.

26. Zhou W, Su SL, Duan JA, Guo JM, Qian DW, Shang EX, et al. Characterization of the active constituents in Shixiao San using bioactivity evaluation followed by UPLC-QTOF and Markerlynx analysis. Molecules. 2010;15(9):6217-30.

27. National Research Council. Guide for the care and use of laboratory animals. Washington, D.C: National Academies Press; 2011.

28. Huang XC, Su SL, Cui WX, Liu P, Duan JA, Guo JM, et al. Simultaneous determination of paeoniflorin, albiflorin, ferulic acid, tetrahydropalmatine, protopine, typhaneoside, senkyunolide I in Beagle dogs plasma by UPLC-MS/ MS and its application to a pharmacokinetic study after Oral Administration of Shaofu Zhuyu Decoction. J Chromatogr B. 2014;962:75-81.

29. Liu K, Yan LQ, Yao GC, Guo XJ. Estimation of p-coumaric acid as metabolite of E-6-O-p-coumaroyl scandoside methyl ester in rat plasma by HPLC and its application to a pharmacokinetic study. J Chromatogr B. 2006;831(1-2):303-6.

30. Bi XL, Gong MR, Di LQ. Review on prescription compatibility of Shaoyao Gancao Decoction and reflection on pharmacokinetic compatibility mechanism of traditional Chinese medicine prescription based on in vivo drug interaction of main efficacious components. Evid Based Complement Alternat Med. 2014; Article ID 208129, 8 pages.

31. Su SL, Xue P, Ouyang Z, Zhou W, Duan JA. Study on antiplatelet and antithrombin activitives and effective components variation of PuhuangWulingzhi before and after compatibility. Zhongguo Zhong Yao Za Zhi. 2015; 40(16):3187-93.

32. Cheng M, Yang LX, Yang LJ, Feng XF, Wang HJ. GC-MS analysis on volatile components of wild Trogopterus Faeces from Laishui county of Hebei province. Zhongguo Zhong Yao Za Zhi. 2011;36(24):3480-3.

33. Qi JP, Sun MJ, Ping QE, Zhuang J, Li JR, Peddie F, et al. The Mechanisms for enhanced oral absorption of hydroxysafflor yellow A by Chuanxiong volatile oil. Planta Med. 2010;76(8):786-92.

\section{Submit your next manuscript to BioMed Central and we will help you at every step:}

- We accept pre-submission inquiries

- Our selector tool helps you to find the most relevant journal

- We provide round the clock customer support

- Convenient online submission

- Thorough peer review

- Inclusion in PubMed and all major indexing services

- Maximum visibility for your research

Submit your manuscript at www.biomedcentral.com/submit
) Biomed Central 